\title{
DIESEL IN A FIX
}

2/IIIIIIIIIIIIIIIIIIIIIIIIIIIIIIIIIIIIIIIIIIIIIIIIIIIIIIIIIIIIIIIIIIIIIIIIIIIIIIIIIIIIIIIIIIIIIIIIIIIIIIIIIIIIIIIIIIIIIIIIIIIIIIIIIII,

\section{Dear Reader,}

The diesel emission cheating scandal, which broke out in the United States last month with the detection of a defeat device fitted in 21 Volkswagen diesel cars that manipulated emission tests, has once again brought to the fore the debate about the fuel being clean and harmless to the environment and human lives. It's difficult at this stage to predict the ramifications of the scandal on the future success of diesel as a fuel, but it has given the naysayers a shot in the arm.

We spoke to experts across the automotive segment to get their views on this, and we weren't surprised that we had a divided house. While some predicted this could be specific to the VW Group, a few others said they won't be surprised if other manufacturers are resorting to tactics to fudge emission-related data. And then there were a few, who said this could lead to the death of diesel as a fuel for vehicles. In current circumstances, the fate of diesel vehicles remains an open question.

The predicament in which Volkswagen finds itself today could be catastrophic for the brand. The $€ 6.5$ bn that it has set aside may not be enough for the company to cover the real damage in terms of loss of sales, recall or brand. The penalties are likely to increase, and so are possible legal cases.

But could this actually be the point, where cities and countries tilt towards electromobility? French capital Paris has already announced that it plans to ban diesel cars from 2020. And there are no reasons why other major cities, be they in Europe, North America or Asia, shouldn’t plan similar drives to gradually move to hybrids and EVs.

The biggest barriers for the growth of electric mobility globally have been cost and range anxiety, and huge amounts of money are being put in to find solutions. On the other hand, stricter standards for diesel emissions could push manufacturers to install technologies that make diesel-powered cars more expensive to produce, thus affecting their popularity.

Time will tell which way the industry moves, but there is no doubt that the VW scandal has rocked the auto industry boat unlike anything previously. Whatever solutions and measures come out of this would only benefit all.

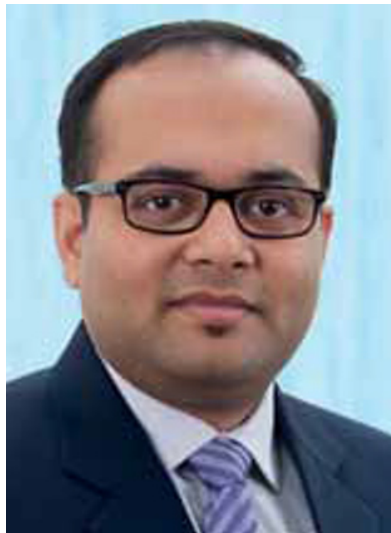

autotechreview.com

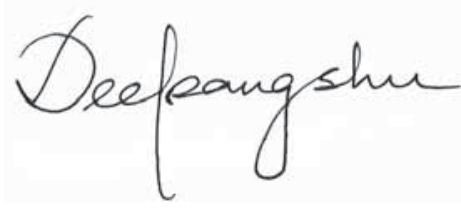

DEEPANGSHU DEV SARMAH

Editor-in-Chief

New Delhi, October 2015 